Process The following lexicons will be reviewed at a highlevel: International Classification of Diseases (ICD) diagnoses and mechanism of injury codes, the International Collaborative Effort (ICE) on Injury Statistics Barell Injury Diagnosis Matrix, the Association for the Advancement of Automotive Medicine's (AAAM's) Abbreviated Injury Scale (AIS), and multiple mapping options from ICD to AIS codes for various versions of each.

Analysis and Outcomes Understanding a systematic and standardized approach to injury coding and mapping is critical to ensure methodologically rigorous and valid activities for injury registry personnel, medical providers, and researchers. There are multiple applications for injury coding and mapping including: mandates for trauma registry accreditation, informing surveillance and interventions, contributing to regional and national trauma databases, facilitating database sharing across various entities, describe community and region-specific epidemiology, guiding injury prevention prioritization efforts, facilitating the evaluation of injury prevention programs' effectiveness, and synergistic collaboration with other groups.

Learning Outcomes The audience will learn about injury coding and mapping using various, standardized lexicons.

\section{D.003 "IDEAS", USING NATIONAL DATA AS A DRIVING FORCE FOR LOCAL ACTION AND ENGAGEMENT}

Eva Vaagland*. Norwegian Safety Forum, Oslo, Norway

10.1136/injuryprev-2021-safety. 164

Context Norwegian Safety Forum is a non-profit organization, a national advocate for safety supported by the Norwegian Ministry of Health, working on three levels; projects and activities on local level, lobbying and policy work on national level, partner and contributor on International level.

National data on injuries are incomplete and difficult to access in Norway. As an advocate for safety we needed a tool to present injury data and prevention measures in an engaging way. We came up with 'IDEAS', the Injury Data Easily Accessible Solution.

Process A grant from InnoMed gave us an opportunity to cooperate with experts on information and service design. With their expertise in communication and our knowledge of available data, and best practice we developed a digital solution.

The solution is based on national data, converted to a local setting, using informative graphic combined with information on injury prevention programs. The goal is to promote local action plans.

Outcomes In February 2019 we launched the prototype. It has been tested by several communities and organizations. The feedback from the test groups was important and we could adjust and improve the solution. The feedback proved that our hypothesis was correct, and we have established a solid base for futher work and a future national solution.

Learning Easy accesesseble data introduced in a logical, comprehensible way, with a local approach, along with information on how to prevent accidents is a way to create more focus and interest for the scope of injuries and the possibilities to prevent them.
$6 \mathrm{E}$ - Mixed Bag - Injury Prevention, March 25, 2021

\section{E.001 PHYSICAL INJURIES AND BURNS AMONG REFUGEES IN LEBANON: PREVENTION, PROGRAMS, AND POLICIES}

${ }^{1}$ Samar Al-Hajj ${ }^{*}$, ${ }^{3}$ Moustafa Moustafa, ${ }^{2}$ Majed El Hechi, ${ }^{1}$ Mohamad Chahrour, ${ }^{1}$ Ali Nasrallah, ${ }^{2}$ Haytham Kaafarani. 'American University of Beirut, Van Dyck Hall, Beirut, Lebanon; ${ }^{2}$ Division of Trauma, Emergency Surgery and Surgical Critical Care, Massachusetts General Hospital, Harvard Medical School, Boston, Massachusetts, USA; ${ }^{3}$ University of Virginia, Richmond, USA

\subsection{6/injuryprev-2021-safety. 165}

Background Refugees are prone to increased risks of injury frequency and severity. In this study, we systematically quantified the prevalence of injuries and burns among refugees in Lebanon and examined injury characteristics, risk factors and outcomes.

Method We conducted a cluster-based population survey across 21 refugee camps in Lebanon from February to April 2019. We used a modified SOSAS tool to record refugees' injuries sustained in the last 12 months. We performed descriptive and multivariate regression analyses to understand the association between variables.

Results of the 1,500 refugees interviewed, 33\% sustained an injury, of which $30 \%$ were occupational injuries. Injuries caused $12 \%$ of refugees' reported deaths. Almost $18.1 \%$ of refugees $(\mathrm{N}=136)$ suffered from burns and $14.8 \%(\mathrm{~N}=111)$ suffered from other injuries (i.e. road traffic, assault). Most burns were sustained by children and caused by boiling liquid $(\mathrm{N}=61,49.6 \%)$, heat contact $(\mathrm{N}=38,30.9 \%)$ and open flame $(\mathrm{N}=17,13.8 \%)$. Injuries mainly affected extremities $(43 \%, \mathrm{p}<0.001)$ compared to head/face $(26 \%$, $\mathrm{p}<0.001)$, and occurred on the road $(29 \%)$ and in the field $(4 \%)$. Burns was more frequent to face $(34 \%, \mathrm{p}<0.001)$ compared to abdomen $(17 \%, \mathrm{p}<0.001)$ and occurred mostly inside the tent (31\%). Male gender, illiteracy and occupation were associated with increased injuries $(p<0.05)$. Almost $31.4 \%$ of injured suffered long term disability, and $6.8 \%$ required help with mobility.

Conclusion Refugees suffer from a high burden of injury with human and economic repercussions. These findings will guide the allocation of healthcare resources and the design of refugee injury prevention programs and policies.

\section{F - WHS - Program, March 25, 2021}

\section{F.001 INJURY AT WORK: HOW CAN WORKERS CONTRIBUTE TO REDUCE HARMS?}

Trang Khieu*. Worksafe NZ, Wellington, New Zealand

\subsection{6/injuryprev-2021-safety. 166}

Background Work-related injury is a major concern for business, society and community. Identifying workers' role in addressing health and safety (H\&S) risks in the workplace is key for implementing better harm prevention.

Methodology: The survey was conducted from 2014 to 2017. A total of 8489 workers in the four New Zealand high risk industries including construction, forestry, manufacturing 